\title{
Impact of Green financing, FinTech, and financial inclusion on energy efficiency
}

\author{
Hongda Liu ${ }^{1} \cdot$ Pinbo $\mathrm{Yao}^{2} \cdot$ Shahid Latif ${ }^{3} \cdot$ Sumaira Aslam ${ }^{4} \cdot$ Nadeem Iqbal $^{5}$
}

Received: 14 September 2021 / Accepted: 4 October 2021 / Published online: 27 October 2021

(c) The Author(s), under exclusive licence to Springer-Verlag GmbH Germany, part of Springer Nature 2021

\begin{abstract}
In modern times, enhancing energy efficiency is one of the core agenda items for the economies to progress the world. United Nations general assembly has recommended increasing energy efficiency by considering the SDG-7 guidelines. In the contemporary period, E7 economies are deficient in producing the financial resources to ensure the availability of funds for the acquisition of energy efficiency. COVID-19 crises, lack of resilience in economies, devastating fiscal burdens, and tight monetary conditions of E7 economies are the major barriers. To resolve such issues, some innovative financing techniques, such as green financing, financial inclusion, and FinTech, were suggested to investigate. However, this research tested the empirical role of financial inclusion, green financing, and FinTech on the energy efficiency of E7 economies. Study findings have shown a significant role of such financing techniques on energy efficiency. Comparatively, green financing is found most fitting and highly supportive financing tool for energy efficiency among the three. The differences in attributes, financing mechanism, funds flow system, transection systems, and variation in support by the financial institution are the main reasons that lessen the role of financial inclusion and FinTech for energy efficiency. However, theorists must revisit the transaction system of FinTech and financial inclusion parameters like green bonds for energy efficiency attainment. Policymakers are suggested to develop viable and energy system-friendly policies to grant green finance to the energy systems of E7 economies, as conveniently as possible.
\end{abstract}

Keywords Green finance $\cdot$ FinTech $\cdot$ Financial inclusion · Energy efficiency $\cdot$ E7 economies

\section{Introduction}

E7 countries have made significant progress over the previous decade to achieve its aim of an effective and sustainable energy system (IEA 2021). The gradual resumption of nuclear power, an increase of renewable energy, and improvements in energy efficiency have reduced

Responsible Editor: Nicholas Apergis

Nadeem Iqbal

nadeem22320@gmail.com

Hongda Liu

liuhoda@163.com

Pinbo Yao

yaopinbo@163.com

Shahid Latif

shahidlatifhcc@gmail.com

Sumaira Aslam

sumaira.aslam@ntu.edu.pk the dependence on fossil fuels which are imported from other countries and contributed to a continuous reduction in greenhouse gas emissions. In this regard, fossil fuels played a substantial role in filling the gap generated by temporary closure of all nuclear power plants in E7 countries. In 2018, greenhouse gas emissions dropped by $13 \%$ as compared to 2013 , returning to the 2009 level. Regardless of all these efforts, E7 countries' reliance on imported fossil fuels is still high. These fossil fuels

1 School of Economics and Management, Tongji University, Shanghai 200092, China

2 School of Management, Shanghai University, Shanghai, China

3 KUBEAC, University of Management \& Technology, Sialkot Campus, Sialkot, Pakistan

4 Faisalabad School of Business, National Textile University, Faisalabad, Pakistan

5 AUSOM, Air University, Islamabad Campus, Islamabad, Pakistan 
account for $88 \%$ of the total energy supply, and the carbon intensity of the energy supply is increased rapidly since 2011. To achieve the objective of low carbon emissions by 2050, E7 countries needs to accelerate the efforts for low carbon technologies, focus on institutional and regularity obstacles, and further enhance the energy market competition (IEA 2021). Based upon these facts, E7 countries need to improve its energy efficiency (Ohta 2020) as E7 countries' energy consumption is primarily derived from fossils which are not considered safe due to the release of greenhouse gas emissions (Pambudi et al. 2017). E7 countries' energy challenges are not new as the country is not affluent in natural resources. Therefore, E7 countries have been in long struggle to fulfil energy needs and bring energy efficiency (Incerti and Lipscy 2020).

The financial sector has become a critical factor in promoting low carbon energy transition (Chenet et al. 2019). Even for achieving the agenda of Sustainable Development Goals promulgated by United Nations along with climate objectives set in the "Paris Climate Agreement," the overall investment requirement at the global level has been projected at US\$100 Billion. For maintaining efficient systems and avoiding harmful impacts of climate, investment requirements regarding energy systems have been estimated at US\$ 1.6-3.8 trillion per year throughout 2020-2050. These statistical evidences reveal the significance of energy efficiency and low carbon energy transition, which is the need of time (Schumacher et al. 2020).

E7 countries are a significant country in low carbon investments and stimulating actions to support the UN agenda on sustainable development goals. Recently, E7 countries' cabinet has approved $\$ 40$ billion for decarbonization in pursuit of green growth energy (The E7 countries Times 2021). This is the manifestation of the significance of green financing for enhancing energy efficiency and low carbon energy transitions. Even in the scholarship of green finance, it has gained considerable attention (Zhang et al. 2019). Considering the significance of green financing, Green Finance Network was launched to bring E7 countries green finance players from all sectors including public as well as private to converse about green financing events in E7 countries (Schumacher et al. 2020). Azhgaliyeva et al. (2020) have asserted that green bonds are important in enhancing energy efficiency. The authors have explained this association in the context of ASEAN countries. Zhang et al. (2020a) have proclaimed, based on a survey, that green financing barriers in China have some impediments in achieving energy efficiency. Based upon these assertions, we argue that in E7 countries, green financing is becoming a significant part of mainstream financial markets to focus on low carbonization so that energy efficiency could be obtained.
In recent years, developments in financial technology (FinTech), particularly in E7 countries, are expected to make a significant contribution in financial inclusion and wellbeing (Yoshino et al. 2020). Financial technology has transformed the way automated operations and processes are delivered and used to strengthen financial services (Ren et al. 2021), and even it has captured the recent attention of scholars as well (Gai et al. 2018). Previous literature has revealed that Fintech has a critical role in addressing poverty, mitigating financial fragility, and facilitating urban development (Cheng and Qu 2020; Fung et al. 2020; Zhang et al. 2020b). Due to Fintech, ecological benefits can also be attained by channelizing renewable energy (Deng et al. 2019). Butu et al. (2021) have argued that multilateral financial institutions (MFIs) and combination of internet strength regarding based community organizations can effectively get renewable energy finance. This appears to be a rational argument as Liao and Ren (2020) have proclaimed that recent technological advancements can enhance energy efficiency at a faster pace.

Arguing on Fintech and green finance, Dorfleitner and Braun (2019) have asserted that Fintech can mobilize green finance prospectively because Fintech provides facilitation to access to new sources of finance and investment. Fintech role is evident in providing green financing by combining big data and artificial intelligence to accelerate the transition to a green economy (Wang et al. 2021a, b). Cen and $\mathrm{He}$ (2018) have stated that Fintech contributes to ensuring green finance. Schletz et al. (2020) have argued that energy efficiency interventions are slower due to certain market barriers, and Blockchain technology, which is an example of Fintech, can address such obstacles by altering energy systems designs. In terms of green finance, Tu and Rasoulinezhad (2021) have voiced that the issuance of green bonds can augment the capital flow to ensure energy efficiency. Based on these proclamations, green finance could play a role in providing energy finance, and Fintech has the same position as well. Yet, part of Fintech is considered more robust in energy finance because Fintech facilitates green financing. Nassiry (2018) has also corroborated this argument that Fintech is extremely important for unlocking green finance. In E7 countries, the focus on Fintech have come later compared to other countries such as the UK, China, Singapore, and the USA. Research has also revealed that E7 countries have considered the incorporation of Fintech in their banking system to make it more robust (Kitamura 2020). Therefore, we argue that green finance and Fintech jointly can be a potential contributor in mitigating the energy efficiency dilemmas in E7 countries' economy.

It is evident that financial development is an inseparable component of the growth process (Le et al. 2019) and financial inclusion is a significant dimension of financial development (Le et al. 2020). Financial inclusion develops 
feasibility in investing in green technology by granting easy access to financial schemes, and by promoting financial inclusion, clean energy technology can be attained (Le et al. 2020) because inclusive financial systems can have a better impact on environmental practices. Based upon these assertions, we argue that financial inclusion could have a significant impact on achieving energy efficiency. Previous literature has revealed the significance of Fintech, green finance, and financial inclusion for energy efficiency but rare studies are available in which this nexus is empirically tested particularly in context E7 countryside economy.

In summary, this paper has contributed to the existing body of knowledge in three ways: (1) This is probably the first research in which nexus of Fintech, green financing, financial inclusion, and energy efficiency is unboxed keeping in view recent Fintech advancements and its potential role in energy efficiency; (2) We have argued that Fintech is basically a facilitator in provision of green finance; therefore, in current debates specially in E7 countries' context, Fintech is essential for fostering green financing; (3) We applied data envelopment analysis to test our hypothesis which has added a unique perspective in comprehending results.

The rest of the paper is organized as follows: the "Literature review" section summarizes the literature review and explains the development of hypotheses; the "Methodology" section briefly discusses the empirical model and usage of data; the "Results and discussion" section describes the practical results of the study; the "Conclusion and implications" section throws light on conclusion and policy recommendations.

\section{Literature review}

\section{Green finance and energy efficiency}

Energy has a significant role in economic growth worldwide because it is a required input element in economic activities (Yu and He 2020). In this regard, consumption of energy has been enhanced as well at a rapid pace by several countries (Wang et al. 2015). There are two challenges that are prevalent in global energy transformation stage, i.e., escalated demand for energy and carbon emissions limitations ( $\mathrm{Yu}$ et al. 2020). In a report of British Petroleum's (BP 2019) World Energy Outlook, the same challenge has been discussed which is to fulfill the rising demand of energy and at the same time, lowering carbon emissions. According to International Energy Agency, residential, transportation, and industrial sectors are major consumers of energy. Therefore, energy efficiency is of high concern and improvements in it have the potential to significantly cut energy usage and $\mathrm{CO} 2$ emissions. Several countries have also legislated in order to increase the energy efficiency (Locmelis et al. 2020).

The significance of green finance in energy efficiency is of high concern. Finance is considered the engine of energy projects and financial institutions also portray their interest in such projects. In Asian perspective, there is a major shift in investment horizons and many countries in Asia are promoting green finance (Azhgaliyeva and Liddle 2020). Arguing on green finance, it is used in financing projects having environmental concerns. Although unified definition of green projects is not agreed upon, yet these projects can be considered as green such as renewable energy, energy efficiency, and prevention of pollution (Azhgaliyeva and Liddle 2020). Particularly in energy efficiency projects, green bonds are frequently used (Azhgaliyeva and Liddle 2020).

Raberto et al. (2019) have stated that with the help of green investment opportunities, transition of more energy efficient production can be fostered. In a recent study (Tolliver et al. 2021), it has been argued that not only in China and South Korea, E7 countries is also increasing issuance of green bonds and green patent registrations for increasing the energy efficiency. Arguing on E7 countries' green bond market, it is on rise on a continuous basis (Fig. 1). Financial corporations led issuance of green bonds and captured $32 \%$ (US \$ $3.4 \mathrm{Bn}$ ) of market share whereas government-backed entities issue green bonds with a market share of $29 \%$ (US \$3Bn).

Many empirical studies have been conducted to demonstrate the effect of green financing on energy efficiency. For instance, Pavlyk (2020) have found, by applying bibliometric analysis, that green investment enhances the renewable energy and energy efficiency. The author has found the increasing publication tendency on the subject of energy efficiency and green finance. Green finance facilitates investment in energy initiatives and fosters green economic growth (Peng and Zheng 2021). Based upon stochastic frontier analysis procedure, Peng and Zheng (2021) have identified the promotion effect of green finance on energy efficiency. Azhgaliyeva et al. (2020) investigated the Association of Southeast Asian Nations' (ASEAN) issuance of green bonds and green bond policies and discovered that two-thirds of the ASEAN's green bonds were used to financing renewable energy and energy efficiency projects in order to increase energy efficiency and meet the region's accelerated growth in energy availability. Taghizadeh-Hesary and Yoshino (2019) have asserted on the basis of theoretical investment models; for increasing returns on green energy projects, green credit can facilitate to reduce the green finance risks. Furthermore, Zheng et al. (2020) discovered that financial sector might aid the establishment of a green economy. All these studied have exhibited that green finance can lead to achieve energy efficiency. 
Fig. 1 Improvement in energy efficiency (over the year)

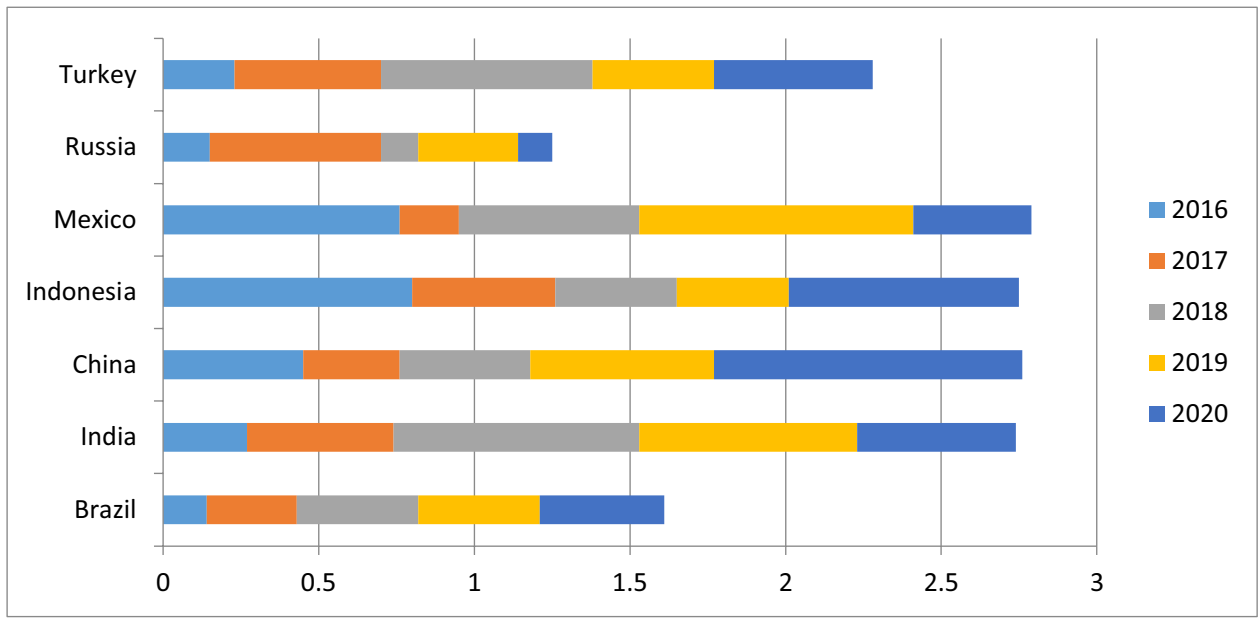

\section{FinTech and energy efficiency}

Fintech is a relatively novel financial industry in which technology is used to enhance financial activity (Schueffel 2016). Leong and Sung (2018) define Fintech as "any new concepts that improve financial service operations through the provision of technology solutions tailored to specific company conditions." "Financial technology or known as 'fintech' is an emerging concept as a core disruptor of every aspect of today's financial system. Fintech covers everything from mobile payment platforms to High-Frequency Trading (HFT), and from crowd funding and virtual currencies to block chain" (Kim 2018, p. 200). Fintech innovation was generated by advancements in e-finance and mobile technologies for financial institutions during the 2008 global financial crisis. Integration of e-finance innovation, internet technology, social networking services, social media, artificial intelligence, and big data have characterized this trend (Lee and Shin 2018). Due to these financial technology advancements, many traditional financial organizations, such as banks, are forced to rethink their business models (Davis et al. 2017). Additionally, Gimpel et al. (2018) have stated that Fintech Startups are even emerging in providing services such as lending, asset management, and insurance.

Now in E7 countries' economy, digital transformation is taking place at a fast pace (Khare et al. 2020). Particularly in such digital transformation, financial technology (Fintech) is in high debate since last decade. Zavolokina et al. (2016) have investigated how Fintech terminology is utilized in science journals and empirical materials, encompassing renowned newspapers and working papers of research firms. "Their study found 38 different definitions, including the application of IT in finance, start-ups, services, technologies, and companies in the financial sector as the top 5 meanings" (p. 248). Sironi (2016) has asserted that Fintech is a disruptive force against prevalent financial institutions. Waupsh (2017) has cautioned the USA that without the embracing
Fintech, community banking may perish. In context of E7 countries, Shirota (2016) has asserted that E7 countries needs FinTech now for encouraging non-deposit investment products, moving away from traditional ones (Iqbal et al. 2021b).

E7 countries are the world's third-largest economy after the USA and China, and it is the only Asian country represented in the G7. According to "Fintech Market 2019" which was published by Yano Research Institute, the market size related to Fintech businesses was approximately US \$ 1.9 Billion (JPY 214 billion) and there are expectations for growth over US \$ 10 billion (JPY 1,210 billion). Keeping in view the significance of FinTech in E7 countries, Fig. 2 has revealed the increase in sales value of domestic FinTech market in E7 countries along with projections for 2022.

Digitalization has the potential to significantly accelerate the adoption of energy efficiency and renewable energy technologies, as increased automation and improved data analytics result in decreased energy usage. Moreover, digital technologies give new prospects for the emergence of novel forms of funding (IEA 2021). Fintech is considered a disruptive force due to its innovative nature that has significant impact on energy sector. It has significant impact on social, environmental, and ecological advantages in promotion of fund usage for energy efficiency (Deng et al. 2019). Moreover, Kim (2018) has asserted that role of the banks in financing low carbon energy projects is of high significance.

Vogel et al. (2019) have argued that block chain technology has generated ecological and economical sustainable products that ultimately enhanced the circular economy. Zhu et al. (2020) have proclaimed in Chinese context that by provision of decentralized trading systems, block chain can as a facilitator for sustainable consumption of energy in order to achieve circular economy (Huang et al. 2021). The authors further argue that energy sector can be reformed by deployment of block chain technology. Teufel et al. (2019) have also asserted that blockchain-based technologies can 
Fig. 2 Robust responses of findings

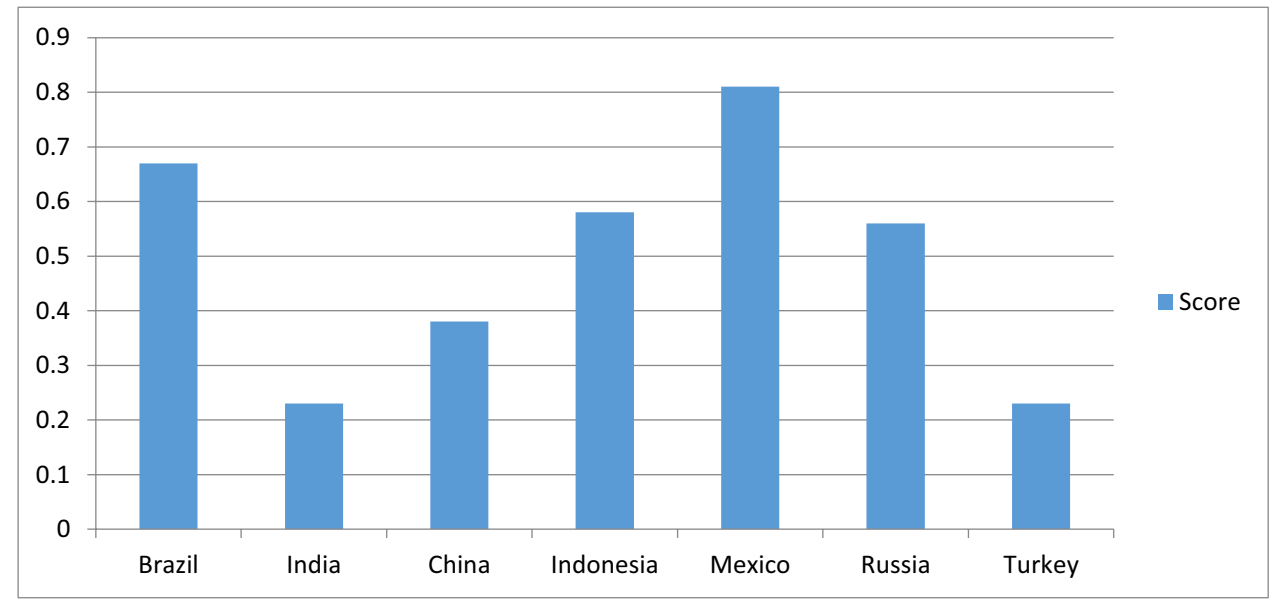

enhance the energy sector and bring significant reforms in it. Anshari et al. (2019) have asserted that Fintech and digital marketplace can augment the agricultural sustainability. Arner et al. (2020) have proclaimed that Fintech functions as a facilitator for financial inclusion, which in turn aids in the achievement of sustainable development. Puschmann et al. (2020) have argued that Fintech and green finance assist in achieving the clean energy that is also mandated in sustainable development goals. All these studies reveal that Fintech can act a facilitating role on achieving energy efficiency.

\section{Financial inclusion and energy efficiency}

Financial inclusion refers to businesses and individuals having access to a range of financial products and services that enable them to meet their needs in a sustainable manner. Previous empirical studies have found the influence of financial inclusion on carbon emissions in several economies such as India (Boutabba 2014); China (Zhang 2011); Tunisia (Farhani and Ozturk 2015); and MENA countries (Charfeddine and Kahia (2019). Le et al. (2020) have studied the impact of financial inclusion on carbon emissions in Asian context. They have found that financial inclusion and energy consumption leads to more emissions in the region. Furthermore, they have argued regarding absence of policy synergies between growing financial inclusion and mitigating emissions. Bayar et al. (2021) have asserted that financial development has the positive influence on energy usage by augmenting economic growth. Access to financial institutions can also have a beneficial effect on energy consumption by facilitating access to credit for individuals and businesses, which will promote investments and upsurge demand for energy-oriented goods ( $\mathrm{Ma}$ and Fu 2020). Nonetheless, financial inclusion makes economic units to have more energy efficient investments and commodities (Bayar et al. 2021).

\section{Methodology}

\section{Data collection}

This research has emphasized on financing opportunities in terms of energy efficiency of E7 economies owing to its association with energy transition. Evaluation of effectiveness pertaining to strategy of energy transition may not be precisely performed without consideration of performance indicators. The first key performance indicator will be "carbon content" during analysis of "carbon footprint" of Megawatt hour (MWh) generated. In accordance with European Environmental Agency (EEA), this query is resolved. Traditionally, key performance indicators exhibit primary sources of energy in production of electricity but in new measurements, secondary usage of energy is also accounted for. Power generated from solar sources, wind, and hydroelectric are some examples of source of renewable energy. Consumption is the key performance indicator that is suggested to use for assessing imports of the country. In this regard, for understanding the concept of "number of consumption days," it is essential to look at its explanation. Measuring ratios regarding import to consumption are not affected by country size such as E7 economies in current research.

In terms of key performance indicators, it is necessary to analyze the influences of future energy revolution on balance of trade of respective economies. In this study, for addressing existence of key performance indicators of severe nature, we employ monitoring mechanism that is based upon physical balancing measurement, for instance, difference between import and export number of consumption days. Measurement of average difference of electric prices between import and export enables us to evaluate exchange intensity (MEDP). The electricity policies of countries have been updated and reason for such updating strategy is to promote green energy shifting. Regardless of unfavorable balance of trade, your approach remains better. Large economies are 
not much influenced by MEDP but it is considered critical for small countries. In our research, we studied the interaction of critical performance indicators during the last three decades. Data for analysis were taken from the World Bank and European Environmental Agency. We analyzed the data specifically covering the period of 2016 to 2020 for estimating results empirically.

\section{Data analysis technique: DEA}

In this study, we have used non-parametric mathematical technique in which decision-making unit (DMU) is quantified. For computation of environmental energy and total factor, CCR model is incorporated. Research design is applied in this section that is depicted in Fig. 1. Prior to commence the operational procedure, conditions were determined such as inputs, outputs that are required, and those outputs that are undesirable. Selection of indicators was based upon significance of objective and subject to appropriate data availability. For each country of E7, different configuration for quantification of numerous energy inputs and outputs for instance, green financing, financial inclusion, Fintech, and energy efficiency, were used in our model. Based upon assertions of Iqbal and Bilal (2021), we assessed if there is any difference between two approaches and whether or not countries might be ranked by effectiveness or efficacy score.

It appears to be possible that an output utilizes the minimum input level. Many a times, dangerous byproducts (e.g., greenhouse gas emissions) are produced as a result of producing fossil fuels in relation to greenhouse gasses. It may be anticipated to lower energy consumption or enhance energy efficiency by producing more units with same or low energy quantity. Li et al. (2021a, b) have asserted that in LEED projects, it is not acceptable to incorporate normal DEA approaches that are meant for just minimization of contaminants. There are many ways for resolving this problem such as providing incentives in order to drive unwanted behavior. Additionally, transformation of outputs can be done that are not desired into those inputs that are desired such as consumption of energy or carbon emissions ( $\mathrm{CO} 2)$ per capita. Furthermore, categorical treatment can be incorporated for dealing unwanted outputs. The main dilemma is related to usage of fossil fuels in context of environmental efficiency. In manufacturing process, usage of less quantity of fuel is dependent upon lowering or enhancing the energy quantity utilization (Anh Tu et al. 2021). Based upon these arguments, we propose the following model:

$$
\begin{aligned}
& E_{1}=\underset{\text { s.t }}{\min \theta} \\
& \sum_{j=1}^{n} \lambda_{j} X_{i j}+S_{i}^{x-}=X_{i j 0}, \mathrm{i}=1, \ldots, \mathrm{m},
\end{aligned}
$$

$\sum_{j=1}^{n} \lambda_{j} e_{l j}+S_{l}^{e-}=\theta e_{l j 0}, 1=1, \ldots, \mathrm{L}$

$\sum_{j=1}^{n} \lambda_{j} y_{r j}+S_{r}^{y+}=y_{r j 0}, \mathrm{r}=1, \ldots, \mathrm{S}$,

$\sum_{j=1}^{n} \lambda_{j} b_{k j}=\theta b_{k j 0}, \mathrm{k}=1, \ldots, \mathrm{K}$,

$\lambda_{j}, S_{i}^{x-}, S_{l}^{e-}, S_{r}^{y+} \geq 0$, for all j, I, 1,

" $\theta$ " represents the energy efficiency and its value is between 0 and 1 . A larger number show the minimum usage of energy by an appliance; therefore, it reveals less emission of carbon. If $\mathrm{S}^{\wedge}(\mathrm{x}-), \mathrm{S} \mathrm{l}^{\wedge}(\mathrm{e}-), \mathrm{S} \mathrm{r}^{\wedge}(\mathrm{y}+)$ approaches zero (e.g., $\mathrm{E} 1=1 ; \theta=1)$, then it reveals that respective country is efficient in environmental sense. On the contrary, if later is the case, a country may be considered inefficient. In such situation, biasness can be seen in comparison of energy efficiency owing to radial efficiency. Hence, it is essential to make investments in those initiatives that are energy efficient.

$\mathrm{E}_{2}=\min \frac{1}{2}\left(\frac{1}{\mathrm{~L}} \sum_{\mathrm{l}=1}^{\mathrm{L}} \theta_{1}^{\mathrm{e}}+\frac{1}{\mathrm{~K}} \sum_{\mathrm{k}=1}^{\mathrm{K}} \theta_{\mathrm{k}}^{\mathrm{b}}\right)$

$\sum_{j=1}^{n} \lambda_{j} X_{i j}+S_{i}^{x-}=X_{i j 0}, \mathrm{i}=1, \ldots, \mathrm{m}$

$\sum_{j=1}^{n} \lambda_{j} e_{l j}+S_{l}^{e-}=\theta_{l}^{e} e_{l j 0}, 1=1 \ldots \ldots \mathrm{L}$,

$\sum_{j=1}^{n} \lambda_{j} y_{r j}-S_{r}^{y+}=y_{r j 0}, \mathrm{r}=1, \ldots, \mathrm{S}$

$\sum_{j=1}^{n} \lambda_{j} b_{k j}=\theta_{k}^{b} b_{k j 0}, \mathrm{k}=1 \ldots \ldots \ldots \mathrm{K}$,

$\lambda_{j}, S_{i}^{x-}, S_{l}^{e-}, S_{r}^{y+} \geq 0$, for all j, I, l,

For analysis of energy efficiency, model 2 shows the measurement of unwanted output that is related to impact of pollutants $\left(\theta \mathrm{k}^{\wedge} \mathrm{b}\right)$, energy input, $\mathrm{CO} 2$ per capita $(\theta$ $\left.1^{\wedge} \mathrm{e}\right)$. This model reveals high energy efficiency and less emissions. For measuring decision-making, non-proportional techniques having unified efficiency are applied by model 2 in order to compute optimum level of energy and environmental efficiency. Based upon the choice of producer, weighting may be varied between environment and energy. Any specific country is regarded as pleasant in environmental perspective and efficient in energy usage, if all slack in model 2 is equal to zero. Therefore, in this research, model 2 is used for assessing the total factor of different financing products in context of E7 economies.

With the assistance of moving average technique, measurement of every DMU effectiveness is done covering a range of time periods. By employing same technique, 
environmental and energy efficiency is assessed at national level, and in this research, we covered a range of time periods. The window comprises $\mathrm{n} * \mathrm{w}$ observations when this approach is used. This leaves only little opportunity to discuss this critical subject. It has been shown that width of the window results in three or four operational cycles. Consistency in findings of environmental and energy efficiency can be obtained by three-wide windows. Regarding first window, it is comprised of first 3 years (e.g., 2016-2019). Following that, another year will be added and further another year of development will be added. If analysis of DEA window is performed, then it is possible to get both radial and nonradial environmental efficiencies (E1 and E2).

\section{Results and Discussion}

\section{Empirical estimation outputs}

The study uses data from City Panel from 290 E7 countries cities from 2011 to 2018 . The information base for research procedure exploration gives a full leading group of green finance approaches utilized as a remedial effect for this analysis. The data set for the text study utilized for this work is the Croutzet and Dabbous (2021), given at the public, commonplace, and civil level by E7 countries' major managerial and administrative elements. We have gathered the resulting terms from the data set green credit, green bond, green activity, and carbon finance to direct our treatment bunch. The urban communities in the treatment bunch are recorded. The underlying time of strategy presentation is viewed as the beginning stage for the arrangement. The table beneath represents the properties based on the information of the city (see Table 1).

Green financing plans remain predicted to reduce energy efficiency in industrial gas and result in greater investments in eco-friendly defense initiatives in E7 countries. Our SDID technique tries to understand the impact of these measures on E7 countries' environmental results. The features of our whole sample are shown in Table 2.

Table 1 Descriptive statistics

\begin{tabular}{lccrl}
\hline Unit & Green financing & $\begin{array}{l}\text { Financial inclu- } \\
\text { sion }\end{array}$ & FinTech & $\begin{array}{l}\text { Energy } \\
\text { efficiency }\end{array}$ \\
\hline Min & 11.31 & 31.64 & 43.01 & 46.79 \\
Max & 7097.024 & 2011.8 & 5128.0 & 1313.5 \\
Kurt & 17.49 & 7.53 & 1.43 & 1046.3 \\
SD & 527.79 & 34.60 & 37.92 & 65.3 \\
Mean & 83.122 & 81.01 & 118.13 & 307.7 \\
Var & 3.49 & 2.01 & 5.19 & 19.55 \\
\hline
\end{tabular}

Nonetheless, E7 countries are proposing post-pandemic economic growth strategies that include trillions of dollars in monetary incentives. Additionally, extensive economic measures will increase energy efficiency. Following the 2008 financial crisis, E7 countries sought rehabilitation. Excessive quantitative easing was introduced by government spending by increasing the amount of money or equity capital that is readily available and credit. Emerging economies, such as E7 countries, have placed a premium on fiscal policy. The advent of the credit crisis had a significant impact on E7 countries' product exports. As a result, E7 countries have moved its focus to consumer spending through increased tax rebates and lower purchasing taxes. These efforts have prioritized the rebuilding industry at the expense of energy consumption and efficiency. E7 countries have shown remarkable resilience in the face of the financial crisis.

Initially dubbed the nation of economic disaster, the E7 countries' government enacted a focused monetary and fiscal policy, as well as unorthodox measures to intervene in the financial market, as well as a financial strategy to lower taxes to boost the entire economy. The following initiatives have aided economic development and mitigated the financial crisis to a degree. Economic growth following extreme events is particularly dependent on energy consumption and efficiency, both of which affect carbon intensity. Indeed, both academics and policymakers are concerned about the recovery in carbon dioxide energy efficiency. Empirical research on the breakdown of rebounding post-COVID greenhouse gas concentrations has indicated that the rapid increase in total energy efficiency contributed greatly to the global leadership resurgence following 2008.

Except for E7 countries, Fig. 1 reveals that energy efficiency is improving across the region. Globally, fuel efficiency is extremely consistent due to relatively equal energy ways. The statistic illustrates the trend toward total efficiency in E7 countries. While this illustrates that a distinct difference exists between E7 countries and other countries, it should be highlighted that this is not typical of Europeans. This may occur as a result of E7 countries' ambitious goals for energy demand. When the fiscal balance shifts sharply in favor of businesses, governments suspend or cut back

Table 2 Energy efficiency

\begin{tabular}{llllll}
\hline & 2016 & 2017 & 2018 & 2019 & 2020 \\
\hline Brazil & 0.14 & 0.29 & 0.39 & 0.39 & 0.40 \\
India & 0.27 & 0.47 & 0.79 & 0.70 & 0.51 \\
China & 0.45 & 0.31 & 0.42 & 0.59 & 0.99 \\
Indonesia & 0.80 & 0.46 & 0.39 & 0.36 & 0.74 \\
Mexico & 0.76 & 0.19 & 0.58 & 0.88 & 0.38 \\
Russia & 0.15 & 0.55 & 0.12 & 0.32 & 0.11 \\
Turkey & 0.23 & 0.47 & 0.68 & 0.39 & 0.51 \\
\hline
\end{tabular}


environmental regulations, as the majority of environmental law is focused on $\mathrm{CO} 2$ (which means a drop in $\mathrm{CO} 2$ ). Controlling and involving the public in environmental protection on a local level may enhance both energy and resource equity. The direct increase in $\mathrm{CO} 2$ emissions as a result of increased vertical fiscal imbalance harmed environmental regulations, resulting in a greater environmental impact. A stronger fiscal balance may contribute to the development of an industrial structure that is likewise inefficient in terms of energy use. As a result, the increasing vertical fiscal imbalance boosted not only energy efficiency, but also had a larger indirect effect, compounding the problem. Increased carbon pollution may be related to an expansion of the industrial structure, as the latter also contributed to an increase in emissions by sustaining the industry structure (see Table 3 ). This study corroborates prior research and the researchers acknowledge it.

The study's conclusions included estimations regarding the relationship between financial inclusion and energy efficiency. Column 1 contains estimates for the pooled data, whereas other columns contain estimates for the GLSS6 and GLSS7 datasets, correspondingly. We interpret normalized coefficients because they allow for easy comparison of different FI and energy efficiency predictions. Recent research indicates that there are two opposing viewpoints on the impact of financial inclusion on energy efficiency. To begin, it is reasonable to expect that significant advancements in an economy's financial sector would result in an increase in people's purchasing power toward energy-intensive commodities with high carbon emissions. On the contrary, a progressive financial system would indeed facilitate increased financing to the renewable energy sector, but would also encourage individuals to invest in larger, energy-efficient commodities as a result of their increased incomes.

As the result of significant energy deceased that occur on the domestic level, energy competence is inextricably linked to energy inefficiency. Low-income households have reaped the greatest benefits from energy efficiency retrofits thus far, with improved health and health care accounting for up to $67 \%$ of the return on investment. Eco-friendly benefits, for

Table 3 Energy efficiency score and energy efficiency rank of study sample

\begin{tabular}{ll}
\hline E7 economies & $\begin{array}{l}\text { Energy } \\
\text { efficiency } \\
\text { score }\end{array}$ \\
\hline Brazil & 0.57 \\
India & 0.41 \\
China & 0.27 \\
Indonesia & 0.85 \\
Mexico & 0.77 \\
Russia & 0.39 \\
Turkey & 0.87 \\
\hline
\end{tabular}

example, lower energy consumption, are self-evident. Correlation matrices illustrate the relationship between financial inclusiveness, energy efficiency, and energy efficiency. Our findings indicate that the IFI index is capable of identifying both the connection between components and the level of financial (association power of $46 \%$ and $89 \%$, respectively). Because Taghizadeh-Hesary et al. (2019) states that the integration coefficients between 0.15 and 0.45 are small, those between 0.30 and 0.60 are medium, and those between 0.60 and 1.00 are large, the effect sizes should be small, medium, and large, accordingly. The correlation between these two values for our FI index and the fund indicator is greater than 0.5. Thus, there is a rather robust, positive, and significant correlation between financial inclusion and energy efficiency.

The temporal relationship between financial inclusiveness and energy efficiency has been a major topic of debate and research. E7 countries' financial inclusion has reached its greatest level in three decades, while the fiscal deficit increased to $7.2 \%$ of GDP at the end of 2018, up from 3.17\% annually. Despite persistent efforts to improve global energy efficiency, the conundrum persists, with rising economies bearing the brunt. Due to the variety of different energy efficiency programs under consideration, the connection between FI and energy efficiency has not been well received. Regrettably, just a few studies have examined this issue utilizing a multidimensional FI index. To determine the relationship between energy efficiency and financial inclusion and between financial inclusion and energy efficiency if FI is endogenous, the distance to the nearest bank should be calculated.

Additionally, we analyze the numerous ways in which FI (financial inclusion) might result in increased household energy efficiency. We find that FI is detrimental to energyefficient families, and this finding holds across a variety of quasi-experimental methodologies. Further solutions to the alternate weighting method for FI and multifarious method of energy efficiency are acceptable too. In terms of family impact, FI regularly affects energy efficiency more in rural areas than in metropolitan areas. Additionally, FI is continuous in assisting in resolving the issue of energy efficiency among human-occupied homes.

Financial development is the process by which new financial technology is introduced (also called FinTech). FinTech is defined by the Economic Constancy Board [14] as financial innovation facilitated by technology that may result in new business models, applications, procedures, or products with a major impact on financial markets and institutions, as well as the provision of financial services. The growth of financial technological advancements is motivated by the fact that the unit cost of financial intermediation has remained relatively constant over the last century. FinTech is the amalgamation of numerous technological advancements 
such as web-based technologies, mobile devices, and networks based upon wireless technology. FinTech is typically classified into three categories: banking, insurance, and regulation. FinTech delivers a new way of funding for the people and a firm, increases credit availability for some disadvantaged segments, and improves the efficiency of financial intermediation. According to a review of global tendencies in the development of the FinTech business, investment in this sector totaled US\$ 111.8 billion in 2018, nearly 6 times the amount invested in 2013.

Cryptocurrency, for instance, NRG coin is FinTech's example for the usage of green energy. NRG coin (NRG) is a green energy cryptocurrency block chain. NRG coin was launched in conjunction with Enervalis, a firm founded in 2013 by FinTech headquartered in Belgium. NGR coin works in light of the fact that the brilliant meter $\mathrm{n}$ its home produces $1 \mathrm{NGR}$ coin for each $1 \mathrm{kWh}$ of environmentally friendly power it infuses into the network when a prosumer produces energy and infuses it into the framework. NRG coin costs $1 \mathrm{kWh}$ of renewable energy used from the grid, regardless of real retail power rates. All NRG currency digital transactions, and their development, are governed by the non-centralized NRG coin protocol and software operating on the peer-to-peer smart meter network. An NRG coin, therefore, serves all smart grid stakeholders (see Fig. 2). It is an incentive for renewable energy facilities, with less danger of policy reform for consumers. NRG coins provide consumers with additional payment alternatives as well as more affordable green energy. If the usage of renewable energy is more, NRG coin's exchange market availability is higher, NRG coin's prices fall, reducing the cost of renewable energy. Finally, since NRG coin is a peer-top cryptocurrency, micropayments, such as energy transactions, can be processed every $15 \mathrm{~min}$ at nearly no overhead expenses.

Table 4 summarizes the test results for the fixed-impacts (FE) model shown in Fig. 1 . The $R$-square value of $72.32 \%$ indicates that the standard model (1) is well suited to the information and records more than $70 \%$ of the separation in the use of sustainable energy. At the 5\% value level, the results reveal that the development of FinTech positively affects the use of environmentally friendly energy (b1 14 0.0019 , p 14 0.0028). These findings confirm the recently

Table 4 Sensitivity analysis proposed view regarding the link between Fintech and sustainable development. The one-unit expansion in FinTech is associated with a $0.1901 \%$ increase in natural energy consumption, suggesting that FinTech development positively affects active energy. Therefore, important guesses are allowed. These findings are somewhat volatile with a combination of information that shows that financial development benefits the sustainable use of energy. The findings of this study amplify previous findings by pointing out that the progress and development of FinTech, which is a hallmark of a special global financial framework, can be recognized as a key factor in increasing the use of unconventional energy. These findings add to the combination of information on sustainable energy use and financial improvement by measuring Fintech's impact on environmentally friendly energy use and demonstrating its value as a contributing factor to sustainable energy use.

\section{Discussion}

A key point in this study is to examine the impact of FinTech's extension on sustainable energy use. In addition, future data on sustainable energy consumption, GDP, unconventional speculation, energy expenditure, quantity list, and GDP development per capita were obtained during the study period. The model examining the impacts of FinTech's development on non-environmental energy use was determined using the Driscoll-Kraay direct impact model. These defects are "strong in heteroscedasticity and autocorrelation and are strong in common types of transversal and transient dependence." The data reveal that the potential for FinTech events and the use of conservation energy have a positive relationship (Anh Tu et al. 2021). The results set FinTech as a response to increasing the use of conservation energy in the energy sector (Iqbal et al 2021a).

The results of this review also have some critical considerations for policymakers who should consider the newly developed developments and be used to plan a powerful strategy in the area of financial management. FinTech offers better ways to heal power generation and energy consumption, new tools to address complex electrical matrices made by small, diverse customers, new investment openings, and new tools to deal with this risk ( $\mathrm{Li}$ et al. 2021a, b). The FinTech industry also facilitates information attention and dissemination. These cumulative advantages are proved to promote renewable energy sector development (Alemzero et al. 2021).

Green financing has a huge impact on energy efficiency. Energy efficiency may be improved through two tactics: distinct policy groups dedicated to achieving energy poverty targets and a complete execution strategy for policies aimed at families with low income through financial inclusion $(\mathrm{Li}$ et al. 2021a, b). In other words, governments and politicians 
should develop regulations to decrease home energy consumption and greenhouse gas releases, and then completely appliance them to mitigate the impact of energy poverty on low-income families. Three indicators, per capita electricity ingesting, per capita monthly energy expenditure, and per capita LPG ingesting, contribute $27.3 \%, 18 \%$, and $13.9 \%$, respectively, to the HEPI scores with a positive correlation, indicating that they are the primary energy variables. Additionally, the research demonstrates the significance of energy facilities, mainly the part of electronic devices in energy deficiency that controls the energy industry. With $29 \%$ apiece, washing machines and laptops or personal computers make the largest optimistic contributions among equipment/appliances, followed by cooling devices (i.e., an air conditioner) with $21 \%$. Refrigerators, on the other hand, contributed the least at $6 \%$. The amount of forest cover, the elevation, radios, televisions, fans, smartphone devices, and traditional fuels all have a deleterious effect. The facts discussed above have a direct impact on energy strategies in the world's largest energy producers and consumers.

\section{Conclusion and implications}

Additionally, the findings reveal that, in comparison to the lower-middle-income category, the other two income categories have a significantly greater impact on trade openness and carbon dioxide energy efficiency. As a result of the influence of foreign direct investment, trade openness has a greater effect on the carbon intensity of GDP than having a mobile. GDP has a considerable impact on the carbon intensity of trade openness. We investigate two significant reasons for this. Initially, the economic scale continues to expand in lockstep with the growth of an international business, particularly in less developed countries. While it has facilitated worldwide business and economic expansion, it has also resulted in excessive resource use and continuous environmental damage, despite efforts to improve energy efficiency. Additionally, global economic integration improves the global labor division and fosters international economic cooperation. When nations compete on a global scale, they make good use of their inherent resources and advantages in order to gradually transform their industrial structure. GDP stimulates transfers of environmental damage sectors from less developed countries to developed nations, resulting in increased energy efficiency in less developed nations.

As mentioned in the theoretical hypothesis, the effects of trade openness on carbon intensity affect the economic phase of E7 countries. Thus, this research shows E7 countries' economy into three income categories based on World Bank categorization criteria: high income, high-medium income, and low-middle income. We evaluated the relationship between trade openness and carbon intensity in E7 countries. The results are summarized in Fig. 1. To begin, various income groups have cut points, and E7 countries have a double threshold effect, demonstrating that trade openness has a nonlinear effect on the carbon intensity of different income groups. The key finding of this study is that the coefficient in the high-income group is negative, indicating that international commerce results in a decrease in carbon intensity in E7 countries. In comparison, the coefficient for the middle-income group is positive, indicating that international commerce contributes to increased carbon intensity. Just because the coefficient is negative for low-income households, the technology advancements and structural adjustments brought about by trade developments simplify the process of reducing energy efficiency. Additionally, the data indicate that, in comparison to the lowermiddle-income group, the other two income groups have a greater impact on trade openness and carbon dioxide energy efficiency.

Author contribution Write up, corrections, and data collection: Hongda Liu; review, analysis, and supervision: Pinbo Yao; visualization, editing, writing of draft: Shahid Latif; editing and visualization: Sumaira Aslam; conceptualization and methodology: Nadeem Iqbal.

Availability of data Data is publicly available at mentioned sources in data section.

\section{Declarations}

Ethics approval and consent to participate We declare that we have no human participants, human data, or human issues.

Consent for publication We do not have any individual person's data in any form and we give consent for publication in true letter and spirit.

Competing interests The authors declare no competing interests.

\section{References}

Alemzero DA, Iqbal N, Iqbal S, Mohsin M, Chukwuma NJ, Shah BA (2021) Assessing the perceived impact of exploration and production of hydrocarbons on households perspective of environmental regulation in Ghana. Environ Sci Pollut Res 28(5):5359-5371

Anh Tu C, Chien F, Hussein MA, Ramli MMY, Psi MM MSS, Iqbal S, Bilal AR (2021) Estimating role of green financing on energy security, economic and environmental integration of BRI member countries. Singap Econ Rev

Anshari M, Almunawar MN, Masri M, Hamdan M (2019) Digital marketplace and FinTech to support agriculture sustainability. Energy Procedia 156:234-238

Arner DW, Buckley RP, Zetzsche DA, Robin V (2020) Sustainability, FinTech and financial inclusion. Eur Bus Org Law Rev 21(1):7-35

Azhgaliyeva D, Liddle B (2020) Introduction to the special issue: scaling up green finance in Asia 
Azhgaliyeva D, Kapoor A, Liu Y (2020) Green bonds for financing renewable energy and energy efficiency in South-East Asia: a review of policies. J Sustain Financ Invest 10(2):113-140

Bayar Y, Ozkaya MH, Herta L, Gavriletea MD (2021) Financial development, financial inclusion and primary energy use: evidence from the European Union transition economies. Energies 14(12):3638

Boutabba MA (2014) The impact of financial development, income, energy and trade on carbon emissions: evidence from the Indian economy. Econ Model 40:33-41

British Petroleum (2019) Outlook. BP Energy. British Petroleum, London

Butu HM, Nsafon BEK, Park SW, Huh JS (2021) Leveraging community based organizations and fintech to improve small-scale renewable energy financing in sub-Saharan Africa. Energy Res Soc Sci 73:101949

Cen T, He R (2018) Fintech, green finance and sustainable development. Adv Soc Sci Educ Hum Res 291:222-225

Charfeddine L, Kahia M (2019) Impact of renewable energy consumption and financial development on $\mathrm{CO} 2$ emissions and economic growth in the MENA region: a panel vector autoregressive (PVAR) analysis. Renew Energy 139:198-213

Chenet H, Zamarioli L, Kretschmer B, Narvaez R (2019) From transformational climate finance to transforming the financial system for climate

Cheng M, Qu Y (2020) Does bank FinTech reduce credit risk? Evidence from China. Pac Basin Financ J 63:101398

Croutzet A, Dabbous A (2021) Do FinTech trigger renewable energy use? Evidence from OECD countries. Renew Energy 179:1608-1617

Davis K, Maddock R, Foo M (2017) Catching up with Indonesia's fintech industry. Law Financ Mark Rev 11(1):33-40

Deng X, Huang Z, Cheng X (2019) FinTech and sustainable development: evidence from China based on P2P data. Sustainability 11(22):6434

Dorfleitner G, Braun D (2019) Fintech, digitalization and blockchain: possible applications for green finance. In: The Rise of Green Finance in Europe. Palgrave Macmillan, Cham, p 207-237

Farhani S, Ozturk I (2015) Causal relationship between CO 2 emissions, real GDP, energy consumption, financial development, trade openness, and urbanization in Tunisia. Environ Sci Pollut Res 22(20):15663-15676

Fung DW, Lee WY, Yeh JJ, Yuen FL (2020) Friend or foe: the divergent effects of FinTech on financial stability. Emerg Mark Rev 45:100727

Gai K, Qiu M, Sun X (2018) A survey on FinTech. J Netw Comput Appl 103:262-273

Gimpel H, Rau D, Röglinger M (2018) Understanding FinTech startups-a taxonomy of consumer-oriented service offerings. Electron Mark 28(3):245-264

Huang J, Wang X, Liu H, Iqbal S (2021) Financial consideration of energy and environmental nexus with energy poverty: Promoting financial development in G7 economies. Front Energy Res 666

IEA (2021) E7 countries 2021 - Analysis - IEA. [online] Available at: https://www.iea.org/reports/E7countries-2021. Accessed 5 August 2021

Incerti T, Lipscy PY (2020) The energy politics of E7 countries. In: The Oxford handbook of energy politics

Iqbal S, Bilal AR (2021) Investment performance: emotional beasts are dragging into the darkness of the castle. Glob Bus Rev 09721509211044309

Iqbal S, Bilal AR, Nurunnabi M, Iqbal W, Alfakhri Y, Iqbal N (2021a) It is time to control the worst: testing COVID-19 outbreak, energy consumption and CO 2 emission. Environ Sci Pollut Res 28(15):19008-19020
Iqbal S, Taghizadeh-Hesary F, Mohsin M, Iqbal W (2021b) Assessing the role of the green finance index in environmental pollution reduction. Stud 39(3)

Khare A, Khare K, Baber WW (2020) Why E7 countries' digital transformation is inevitable. In: Transforming E7 countriesese Business. Springer, Singapore, pp 3-14

Kim J (2018) Leverage the financing role of banks for low-carbon energy transition. Financing for Low-carbon Energy Transition, p 189-210

Kitamura K (2020) The future of Fintech in the context of the E7 countriesese Main Bank System. In: Transforming E7 countriesese Business. Springer, Singapore, pp 247-260

Le TH, Chuc AT, Taghizadeh-Hesary F (2019) Financial inclusion and its impact on financial efficiency and sustainability: empirical evidence from Asia. Borsa Istanbul Rev 19(4):310-322

Le TH, Le HC, Taghizadeh-Hesary F (2020) Does financial inclusion impact $\mathrm{CO} 2$ emissions? Evidence from Asia. Financ Res Lett 34:101451

Lee I, Shin YJ (2018) Fintech: Ecosystem, business models, investment decisions, and challenges. Bus Horiz 61(1):35-46

Leong K, Sung A (2018) FinTech (Financial Technology): what is it and how to use technologies to create business value in fintech way? Int Jo Innov Manag Technol 9(2):74-78

Li W, Chien F, Hsu CC, Zhang Y, Nawaz MA, Iqbal S, Mohsin M (2021a) Nexus between energy poverty and energy efficiency: estimating the long-run dynamics. Resour Policy 72:102063

Li W, Chien F, Ngo QT, Nguyen TD, Iqbal S, Bilal AR (2021b) Vertical financial disparity, energy prices and emission reduction: empirical insights from Pakistan. J Environ Manag 294:112946

Liao M, Ren Y (2020) The 'double-edged effect'of progress in energy-biased technology on energy efficiency: a comparison between the manufacturing sector of China and E7 countries. J Environ Manag 270:110794

Locmelis K, Blumberga D, Blumberga A, Kubule A (2020) Benchmarking of industrial energy efficiency outcomes of an energy audit policy program. Energies 13(9):2210

Ma X, Fu Q (2020) The influence of financial development on energy consumption: worldwide evidence. Int J Environ Res Public Health 17(4): 1428

Nassiry D (2018) The role of fintech in unlocking green finance: policy insights for developing countries (No. 883). ADBI Working Paper

Ohta H (2020) The analysis of E7 countries' energy and climate policy from the aspect of anticipatory governance. Energies 13(19):5153

Pambudi NA, Itaoka K, Kurosawa A, Yamakawa N (2017) Impact of hydrogen fuel for $\mathrm{CO} 2$ emission reduction in power generation sector in E7 countries. Energy Procedia 105:3075-3082

Pavlyk V (2020) Assessment of green investment impact on the energy efficiency gap of the national economy

Peng J, Zheng Y (2021) Does environmental policy promote energy efficiency? Evidence from China in the context of developing green finance. Front Environ Sci 299

Puschmann T, Hoffmann CH, Khmarskyi V (2020) How green FinTech can alleviate the impact of climate change-the case of Switzerland. Sustainability 12(24):10691 (IMP)

Raberto M, Ozel B, Ponta L, Teglio A, Cincotti S (2019) From financial instability to green finance: the role of banking and credit market regulation in the Eurace model. J Evol Econ 29(1):429-465

Ren X, Aujla GS, Jindal A, Batth RS, Zhang P (2021) Adaptive recovery mechanism for SDN controllers in Edge-Cloud supported FinTech applications. IEEE Internet Things $\mathbf{J}$

Schletz M, Cardoso A, Prata Dias G, Salomo S (2020) How can blockchain technology accelerate energy efficiency interventions? A use case comparison. Energies 13(22):5869 
Schueffel P (2016) Taming the beast: a scientific definition of fintech. J Innov Manag 4(4):32-54

Schumacher K, Chenet H, Volz U (2020) Sustainable finance in E7 countries. J Sustain Financ Invest 10(2):213-246 ((ref are to be taken))

Shirota M (2016) Nihonban Fintech no Hookoosei: Oubei no Fintech karano shisa. NRI Innovation Symposium 2016. Nomura Soogoo Kenkyuusho. Available https://www.nri.com/jp/event/media forum/2016/pdf/forum241_05.pdf. Accessed 12 Apr 2019

Sironi P (2016) FinTech innovation: from Robo-advisors to goal based investing and Gamification. Wiley, Chichester

Taghizadeh-Hesary F, Yoshino N (2019) The way to induce private participation in green finance and investment. Finance Res Lett 31:98-103

Taghizadeh-Hesary F, Rasoulinezhad E, Yoshino N (2019) Energy and food security: linkages through price volatility. Energy Policy 128:796-806

Teufel B, Sentic A, Barmet M (2019) Blockchain energy: blockchain in future energy systems. J Electron Sci Technol 17(4):100011

The E7 countries Times (2021) E7 countries approves $¥ 4.4$ trillion for green growth. [online] Available at: https://www.E7countrie stimes.co.jp/news/2021/07/08/business/economy-business/greengrowth-budget. Accessed 5 August 2021

Tolliver C, Fujii H, Keeley AR, Managi S (2021) Green innovation and finance in Asia. Asian Econ Policy Rev 16(1):67-87

Tu CA, Rasoulinezhad E (2021) Energy efficiency financing and the role of green bond: policies for post-Covid period. China Financ Rev Int

Vogel J, Hagen S, Thomas O (2019) Discovering blockchain for sustainable product-service systems to enhance the circular economy

Wang H, Zhang Y, Lu X, Nielsen CP, Bi J (2015) Understanding China's carbon dioxide emissions from both production and consumption perspectives. Renew Sustain Energy Rev 52:189-200

Wang C, Li XW, Wen HX, Nie PY (2021a) Order financing for promoting green transition. J Clean Prod 283:125415

Wang L, Wang Y, Sun Y, Han K, Chen Y (2021b) Financial inclusion and green economic efficiency: evidence from China. J Environ Plan Manag 1-32

Waupsh J (2017) Bankruption: how community banking can survive Fintech. Wiley, Hoboken
Yoshino N, Morgan PJ, Long TQ (2020) Financial literacy and Fintech adoption in E7 countries

Yu D, He X (2020) A bibliometric study for DEA applied to energy efficiency: trends and future challenges. Appl Energy 268:115048

Yu D, Dewancker B, Qian F (2020) The identification and rebound effect evaluation of equipment energy efficiency improvement policy: a case study on E7 countries' top runner policy. Energies 13(17):4397

Zavolokina L, Dolata M, Schwabe G (2016) FinTech - what's in a name? In Proceedings of the 37th International Conference on Information Systems (ICIS 2016), AIS, Dublin, Ireland, December $11-14$

Zhang YJ (2011) The impact of financial development on carbon emissions: an empirical analysis in China. Energy Policy 39(4):2197-2203

Zhang D, Zhang Z, Managi S (2019) A bibliometric analysis on green finance: current status, development, and future directions. Financ Res Lett 29:425-430

Zhang M, Lian Y, Zhao H, Xia-Bauer C (2020a) Unlocking green financing for building energy retrofit: a survey in the western China. Energy Strateg Rev 30:100520

Zhang X, Tan Y, Hu Z, Wang C, Wan G (2020b) The trickle-down effect of Fintech development: from the perspective of urbanization. Chin World Econ 28(1):23-40

Zheng S, Fan J, Yu F, Feng B, Lou B, Zou Q, ... Liang T (2020) Viral load dynamics and disease severity in patients infected with SARS-CoV-2 in Zhejiang province, China, January-March 2020: retrospective cohort study. BMJ 369

Zhu S, Song M, Lim MK, Wang J, Zhao J (2020) The development of energy blockchain and its implications for China's energy sector. Resour Policy 66:101595

Publisher's Note Springer Nature remains neutral with regard to jurisdictional claims in published maps and institutional affiliations. 